Book review

\title{
A Watershed in Global Governance: An Independent Assessment of the World Commission on Dams
}

Navroz Dubash, Mairi Dupar, Smitu Kothari, and Tundu Lissu World Resources Institute Washington, DC $136 \mathrm{pp}$.

Kandula Subramaniam

Assistant Editor, The Financial Express, New Delhi, India

International Journal of Regulation and Governance 2(1): 77-78

The book A Watershed in Global Governance: An Independent A ssessment of The World Commission on Dams is an attempt at portraying how an independent organization can be empowered to harness rivers, one of the most important resources of energy, through dams.

Except the three Gorges project in C hina, worldwide, construction of large dams has faced severe bottlenecks and the WCD's (World Commission on Dams') role in this regard had to be assessed independently to judge whether it served the purpose. For that, the authors have made an honest attempt to point out how multi-stakeholder process can play a catalytic role through the experience of the WCD. The book, which has been divided into nine chapters, introduces the subject elaborately (taking as many as four chapters), enabling the reader to understand the background before a judgment is passed. According to the authors, the basic difference between this commission and the past commissions is that the WCD is based on 'representation' rather than 'eminence' and bringing all concerned elements and applying them to an issue was an unparalleled attempt. The authors assess the WCD through three parameters: independence, transparency, and inclusiveness.

In fact, the genesis of WCD, according to the authors, was the result of calls by civil society for an independent review of 
the global experience with large dams, particularly the role of international aid and credit agencies. For that, the WCD adopted a policy of seeking funding with no strings attached. The authors point out that for WCD, maintaining independence by diversifying funding sources was a major accomplishment that enhanced its broader legitimacy. Even though there has been some compromise on this principle of diversification, there is no evidence to suggest any biases. On the issue of transparency, the authors point out that the commission did not meet the stakeholders' 'high' expectations for information disclosure and point that much of this could not have been managed without unrealistic increases in the length and cost of the process. They say that the commission fell short in meeting the basic norms as in acknowledging stakeholder inputs but are quick to point that such experiences should serve as an important feedback for future multi-stakeholder processes.

While those may be the weak points of the WCD, the authors point that the process set in place by the WCD proved to be democratic rather than technocratic. Since its inception, in a short span of time, the WCD had been able to grow and record voices that would have earlier displeased the technical experts. And it is such inclusiveness that sets high expectations for future multi-stakeholder processes. The authors say that it is the WCD process that provided an avenue for greater expression at the national level and stimulated further dialogue across sectors. The full potential of the WCD, according to the authors, lies in the promise of democratization, at both the national and global levels. 